\title{
PISTON
}

\section{Simulasi Kekuatan Mekanik Sudu Turbin Angin Sumbu Horizontal Menggunakan Bahan Steel}

\author{
Syukhur Putraji ${ }^{1}$, Anggito Pringgo Tetuko ${ }^{2}$, dan Djuhana ${ }^{1}$ \\ ${ }^{1}$ Program Studi Teknik Mesin, Universitas Pamulang, Jl. Surya Kencana No.1, Pamulang 15417, \\ Tangerang Selatan, Indonesia. \\ ${ }^{2}$ Pusat Penelitian Fisika, Lembaga Ilmu Pengetahuan Indonesia, Serpong 15314, Tangerang Selatan, \\ Indonesia.
}

E-mail: ajiputra.0105@gmail.com

Masuk:30 Oktober 2020 Direvisi :10 November $2020 \quad$ Disetujui : 30 Desember 2020

\begin{abstract}
Abstrak: Pada sistem turbin angin terdapat salah satu komponen paling penting yaitu sudu turbin yang berfungsi menerima energi angin secara langsung. Agar optimal saat digunakan pemilihan desain dan material yang kuat dalam menahan kecepatan angin yang tinggi menjadi hal yang sangat menentukan. Dalam penelitian ini dengan variasi dimensi sudu dan kecepatan angin sebesar $20 \mathrm{~m} / \mathrm{s}, 25 \mathrm{~m} / \mathrm{s}, 30 \mathrm{~m} / \mathrm{s}$ menggunakan material baja AISI 1020 disimulasikan menggunakan software Simscale dengan metode Finite Element Analysis (FEA) menggunakan boundary condition yaitu force dan fixed support dengan hasil output yaitu von mises stress dan displacement. Dari hasil simulasi desain sudu dan kecepatan angin memiliki pengaruh terhadap distribusi stress dan displacement. Kecepatan angin memiliki pengaruh terhadap desain sudu yang digunakan, semakin besar dimensi sudu yang digunakan maka semakin besar daya yang dihasilkan. Nilai maksimum yang dihasilkan dari simulasi untuk von mises stress dan displacement masih dalam batas aman terhadap batas kekuatan material baja AISI 1020 pada mechanical properties.
\end{abstract}

Kata kunci: Turbin Angin Sumbu Horizontal, Sudu Turbin, Baja AISI 1020, von mises stress, displacement

Abstract: In the wind turbine system, there is one of the most important components, namely the turbine blade which functions to receive wind energy directly. To be optimal when used, the choice of a strong design and material to withstand high wind speeds is very decisive. In this study, with variations in blade dimensions and wind speeds of $20 \mathrm{~m} / \mathrm{s}, 25 \mathrm{~m} / \mathrm{s}, 30$ $\mathrm{m} / \mathrm{s}$ using steel material AISI 1020 simulated using Simscale software with the Finite Element Analysis (FEA) method using boundary conditions, namely force and fixed support. with the output results, namely von mises stress and displacement. From the simulation results, blade design and wind speed have an influence on the stress distribution and displacement. Wind speed has an influence on the design of the blade used, the greater the dimensions of the blade used, the greater the power produced. The maximum value resulting from the simulation for von mises stress and displacement is still within safe limits against the strength limit of AISI 1020 steel material in its mechanical properties.

Keywords: Horizontal Axis Wind Turbine, Turbine Blades, AISI 1020 Steel, Von Mises Stress, Displacement

\section{PENDAHULUAN}

Energi angin adalah energi bersih yang terbarukan dan tidak ada habisnya. energi ini sangat ramah lingkungan dan dapat membantu mengurangi ketergantungan terhadap bahan bakar fosil. Dalam konteks sederhana energi yang dihasilkan pada angin dapat diolah dengan cara memanfaatkan energinya untuk memutarkan baling-baling kincir angin, dimana baling-baling kincir angin ini terhubung dengan poros. Sehingga poros yang telah terhubung dengan generator ikut berputar lalu menimbulkan arus listrik. Karena kincir angin ini dapat menghasilkan energi listrik maka umumnya disebut sebagai Turbin angin [1]. 
Turbin angin pada umumnya memiliki 2 jenis, yaitu turbin angin sumbu horizontal (TASH) dan juga turbin angin sumbu vertikal (TASV). Kedua turbin angin ini dibedakan berdasarkan perbedaan pada bentuk dan cara kerjanya. Turbin angin sumbu horizontal yaitu turbin angin yang memiliki sumbu rotasi horizontal, sedangkan turbin angin sumbu vertikal yaitu turbin angin yang memiliki sumbu rotasi vertikal, dan pada turbin angin sumbu vertikal ini tidak sensitif terhadap perubahan arah angin karena memang pada dasarnya turbin angin jenis ini mampu menangkap angin dari berbagai arah [2].

Pada sistem turbin angin terdapat salah satu komponen paling penting yaitu sudu turbin yang berfungsi menerima energi angin secara langsung. Agar optimal saat digunakan pemilihan desain dan material yang kuat dalam menahan kecepatan angin yang tinggi menjadi hal yang sangat menentukan.

Penelitian ini bertujuan untuk mengetahui pengaruh variasi desain dan kecepatan angin terhadap distribusi stress dan displacement pada sudu turbin yang menggunakan material baja AISI 1020 sehingga dapat diketahui apakah masih dalam batas aman dan dapat optimal untuk digunakan.

\section{METODOLOGI}

Sudu turbin angin sumbu horizontal menggunakan variasi ukuran desain. Software yang digunakan untuk simulasi adalah Simscale. Simscale adalah produk perangkat lunak rekayasa komputer yang berbasis web atau berada pada cloud, Platform berbasis cloud dari Simscale memungkinkan pengguna untuk menjalankan lebih banyak simulasi yaitu Computational Fluid Dynamics (CFD), Finite Element Analysis (FEA) dan Thermal Simulation. Pada penelitian menggunakan Finite Element Analysis (FEA) dengan simulasi dynamic analysis menggunakan boundary condition yaitu force dan fixed support.

Penyelesaian metode elemen hingga menggunakan metode numerik. Media komputer diperlukan untuk menghitung persamaan metode ini, hal ini dikarenakan perhitungan dalam metode ini sangat kompleks. Metode elemen hingga dilakukan dengan cara membagi suatu struktur menjadi beberapa elemen lalu elemen tersebut terhubung melalui nodal [3].

\section{Material Yang Digunakan}

Pada penelitian ini material yang digunakan pada simulasi sudu turbin menggunakan baja AISI 1020 dengan mechanical properties sebagai berikut:

Tabel 1. Mechanical Properties Baja AISI 1020 [4]

\begin{tabular}{lcc}
\hline \multicolumn{1}{c}{ Property } & Value & Units \\
\hline Hardness & 111 & $\mathrm{HB}$ \\
Tensile strength, Ultimate & 394.7 & $\mathrm{Mpa}$ \\
Tensile strength, Yield & 294.8 & $\mathrm{Mpa}$ \\
Young's modulus & $190-210$ & $\mathrm{GPa}$ \\
Poisson's ratio & $0.27-0.30$ & \\
Density $\left(\mathrm{x} 1000 \mathrm{~kg} / \mathrm{m}^{3}\right)$ & $7.7-8.03$ & \\
\hline
\end{tabular}

\section{Desain Variasi Sudu}

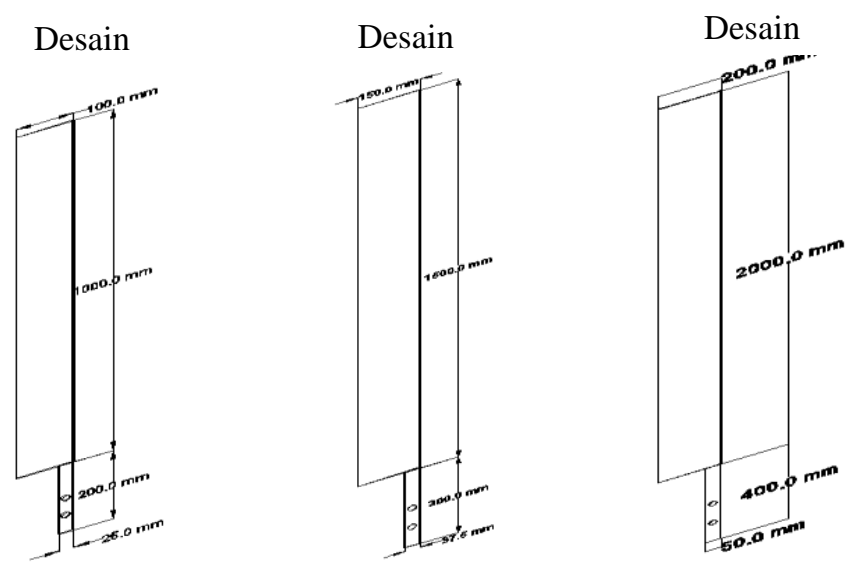

Gambar 1. Desain Variasi Sudu 


\section{Nilai Asumsi}

Berbagai asumsi yang akan digunakan untuk pemodelan dan analisis dinyatakan dibawah ini:

1. Kecepatan angin yang akan digunakan adalah $20 \mathrm{~m} / \mathrm{s}, 25 \mathrm{~m} / \mathrm{s}, 30 \mathrm{~m} / \mathrm{s}$.

2. Koefisien kerja $(\mathrm{Cp}) 0,3$ [5].

3. Efisiensi listrik dan mekanik diambil masing 0,95 dan 0,90 [5].

4. Untuk luas (A) akan mengikuti desain sudu.

5. Density udara yang digunakan adalah $1,225 \mathrm{~kg} / \mathrm{m}^{3}[5]$.

Untuk menentukan nilai gaya pada simulasi sebagai input pada force, digunakan rumus sebagai berikut: [6]

\section{Daya Angin}

$$
P=0,5 \times \rho \times A \times C p \times v^{3} \times \eta e \times \eta m
$$

Dimana $P$ adalah tenaga dalam watt (watt), A adalah luas permukaan sudu turbin $\left(\mathrm{m}^{2}\right), \rho$ adalah massa jenis udara $\left(1,225 \mathrm{~kg} / \mathrm{m}^{3}\right), C p$ adalah koefisien kerja $(0,35), v$ adalah kecepatan angin $(\mathrm{m} / \mathrm{s}), \eta e$ adalah efisiensi listrik dan $\eta m$ adalah efisiensi mekanik.

\section{Kecepatan Rotasi}

$n=\frac{60}{\pi} \frac{v}{2 R}(2)$

Dimana $n$ adalah kecepatan rotasi (RPM), $v$ adalah kecepatan angin $(\mathrm{m} / \mathrm{s})$ dan $R$ adalah jari-jari sudu turbin $(\mathrm{mm})$.

\section{Torsi (N/mm)}

$$
T=9,55 \times 10^{6} \frac{P}{n}
$$

Dimana $T$ adalah torsi yang dibutuhkan, $P$ adalah Daya $(\mathrm{kW})$ dan $n$ adalah kecepatan rotasi (RPM)

\section{Gaya $(\mathbf{N})$}

$$
F=\frac{T}{R}
$$

Dimana $F$ adalah Gaya (N), $T$ adalah Torsi (N.mm) dan $R$ adalah jari-jari sudu turbin (mm).

\section{HASIL DAN PEMBAHASAN}

Pada tabel dibawah merupakan hasil perhitungan dengan nilai asumsi dan rumus sehingga diperoleh data sebagai berikut:

Tabel 2. Hasil Perhitungan Gaya

\begin{tabular}{cccccc}
\hline $\begin{array}{c}\text { Variasi } \\
\text { Desain }\end{array}$ & $\begin{array}{c}\text { Kecepatan } \\
\text { angin }\end{array}$ & $\begin{array}{c}\text { Daya } \\
(\mathrm{kW})\end{array}$ & RPM & Torsi (N.mm) & Gaya (N) \\
\hline \multirow{2}{*}{ A } & $20 \mathrm{~m} / \mathrm{s}$ & 0.126 & 382 & 3150 & 6.30 \\
& $25 \mathrm{~m} / \mathrm{s}$ & 0.245 & 478 & 4895 & 9.79 \\
& $30 \mathrm{~m} / \mathrm{s}$ & 0.424 & 573 & 7067 & 14.13 \\
\hline \multirow{2}{*}{ B } & $20 \mathrm{~m} / \mathrm{s}$ & 0.283 & 255 & 10599 & 9.79 \\
& $25 \mathrm{~m} / \mathrm{s}$ & 0.552 & 318 & 16577 & 22.10 \\
& $30 \mathrm{~m} / \mathrm{s}$ & 0.954 & 382 & 23850 & 31.80 \\
\hline \multirow{2}{*}{ C } & $20 \mathrm{~m} / \mathrm{s}$ & 0.503 & 191 & 25150 & 25.15 \\
& $25 \mathrm{~m} / \mathrm{s}$ & 0.982 & 239 & 39239 & 39.24 \\
& $30 \mathrm{~m} / \mathrm{s}$ & 1.697 & 287 & 56568 & 56.57 \\
\hline
\end{tabular}


Dari hasil perhitungan tersebut nilai gaya digunakan untuk pemasukan data dalam boundary condition pada force dan fixed support dengan memilih pegangan sebagai tumpuan pada sudu turbin. Berikut merupakan hasil dari simulasi yang telah dilakukan:

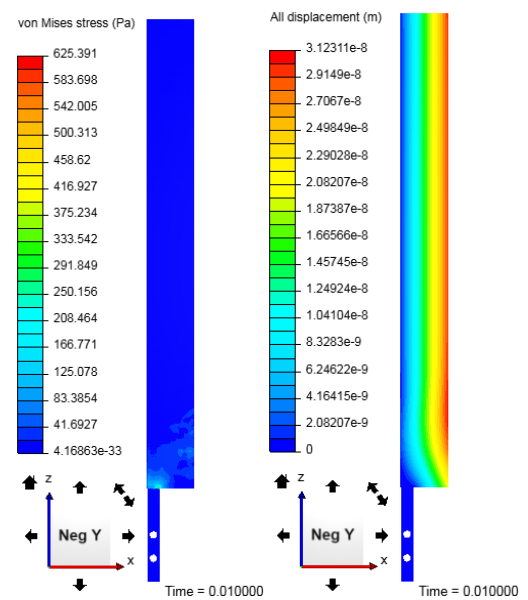

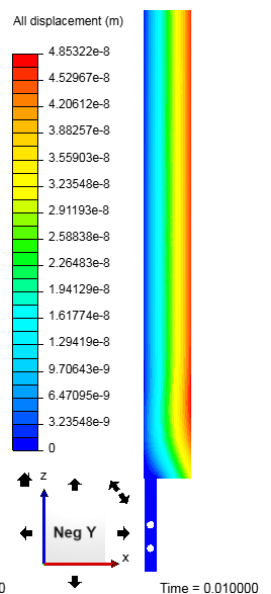

Gambar 2. Simulasi Desain A Kec. $20 \mathrm{~m} / \mathrm{s}$
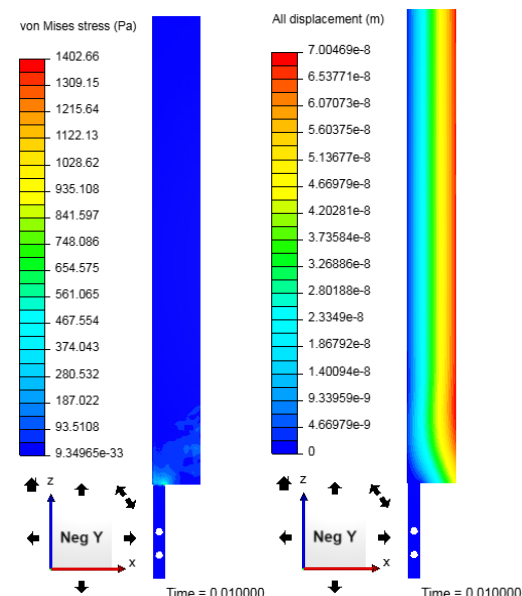

Gambar 3. Simulasi Desain A Kec. $25 \mathrm{~m} / \mathrm{s}$

Hasil simulasi berupa kontur warna yang diartikan dalam setiap warna menunjukan kenaikan tingkat stress, pada area warna biru tua yaitu area yang memiliki tingkat stress paling rendah, warna biru muda hijau dan kuning memiliki tingkat stress sedang, hingga merah yang menandai tingkat stress paling tinggi.

Pada hasil simulasi pada desain A dengan kecepatan 20,25, $30 \mathrm{~m} / \mathrm{s}$ menunjukan kenaikan pada nilai von mises stress dan Displacement seiring nilai gaya semakin besar, dengan nilai maksimum von mises stress adalah 625.4, 971.8, 1402.6 Pa. Letak stress tertinggi terjadi pada sambungan antara sudu dengan pegangan yang merupakan tumpuan beban dari berat keseluruhan sudu. Nilai maksimum Displacement adalah 3.12311e-8, $4.85322 \mathrm{e}-8,7.00469 \mathrm{e}-8 \mathrm{~m}$. Area yang menunjukan tingkat displacement tertinggi adalah pada bagian depan sudu yang memiliki ketebalan yang lebih tipis.

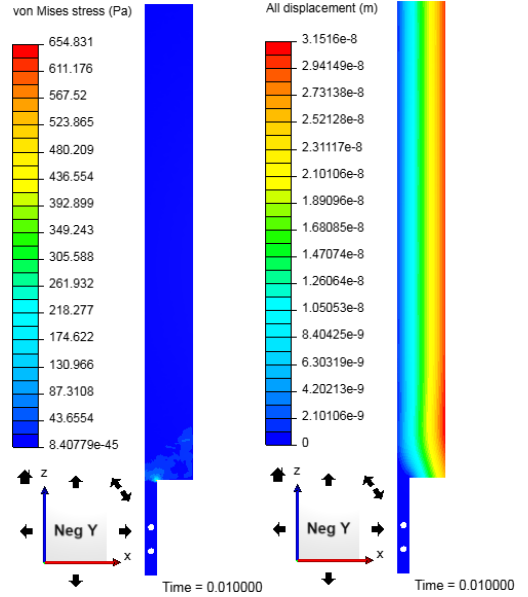

Gambar 5. Simulasi Desain B Kec. $20 \mathrm{~m} / \mathrm{s}$
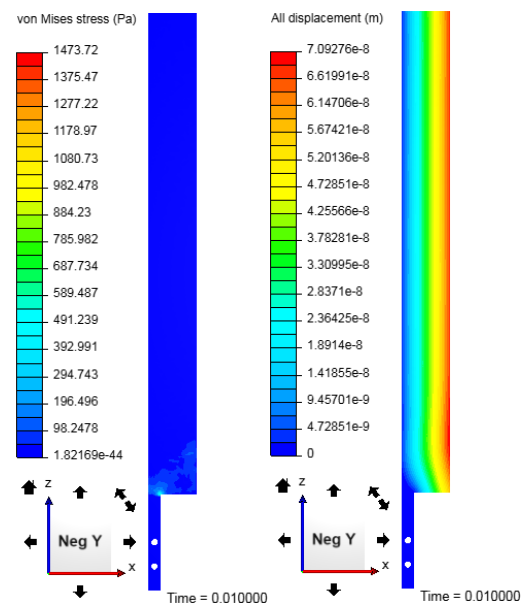

Gambar 6. Simulasi Desain B Kec. $25 \mathrm{~m} / \mathrm{s}$

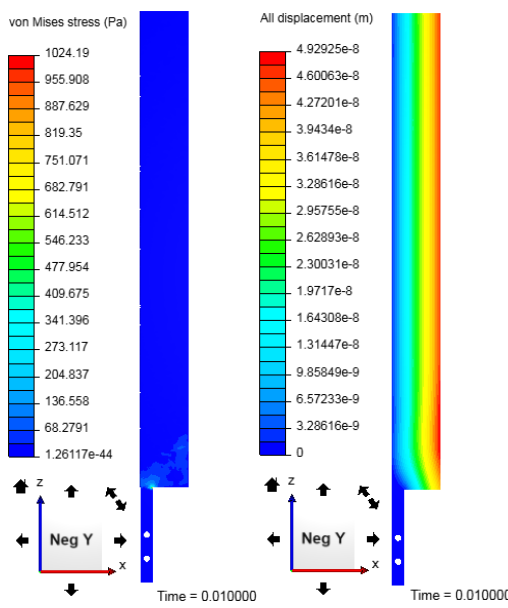

Gambar 7. Simulasi Desain B Kec. $30 \mathrm{~m} / \mathrm{s}$

Pada hasil simulasi pada desain B dengan kecepatan 20,25, $30 \mathrm{~m} / \mathrm{s}$ menunjukan kenaikan pada nilai von mises stress dan Displacement seiring nilai gaya semakin besar, dengan nilai maksimum von mises stress adalah 654.8, 1024.1, $1473.7 \mathrm{~Pa}$. letak stress tertinggi terjadi pada sambungan antara sudu dengan pegangan yang merupakan tumpuan beban dari berat keseluruhan sudu. Nilai maksimum Displacement adalah 3.15159e-8, 4.92925e-8, 7.09276e-8 m. Area yang menunjukan tingkat displacement tertinggi adalah pada bagian depan sudu yang memiliki ketebalan yang lebih tipis. 

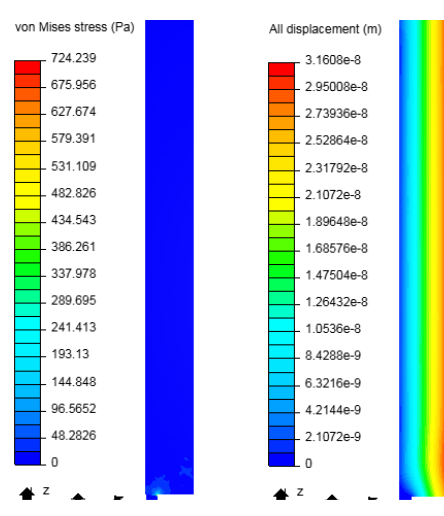

Gambar 8. Simulasi Desain C Kec. $20 \mathrm{~m} / \mathrm{s}$

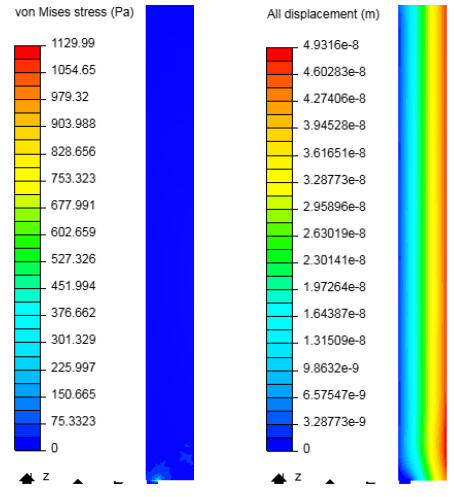

Gambar 9. Simulasi Desain C Kec. $25 \mathrm{~m} / \mathrm{s}$

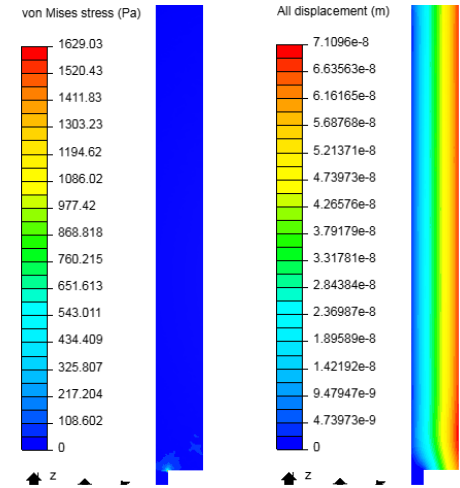

Gambar 10. Simulasi Desain C Kec. 30 m/s

Pada hasil simulasi pada desain $\mathrm{C}$ dengan kecepatan 20,25, $30 \mathrm{~m} / \mathrm{s}$ menunjukan kenaikan pada nilai von mises stress dan Displacement seiring nilai gaya semakin besar, dengan nilai maksimum von mises stress adalah 724.2, 1129.9, $1629 \mathrm{~Pa}$. letak stress tertinggi terjadi pada sambungan antara sudu dengan pegangan yang merupakan tumpuan beban dari berat keseluruhan sudu. Nilai maksimum Displacement adalah 3.19521e-8, 4.9316e-8, 7.1096e-8 m. Area yang menunjukan tingkat displacement tertinggi adalah pada bagian depan sudu yang memiliki ketebalan yang lebih tipis.

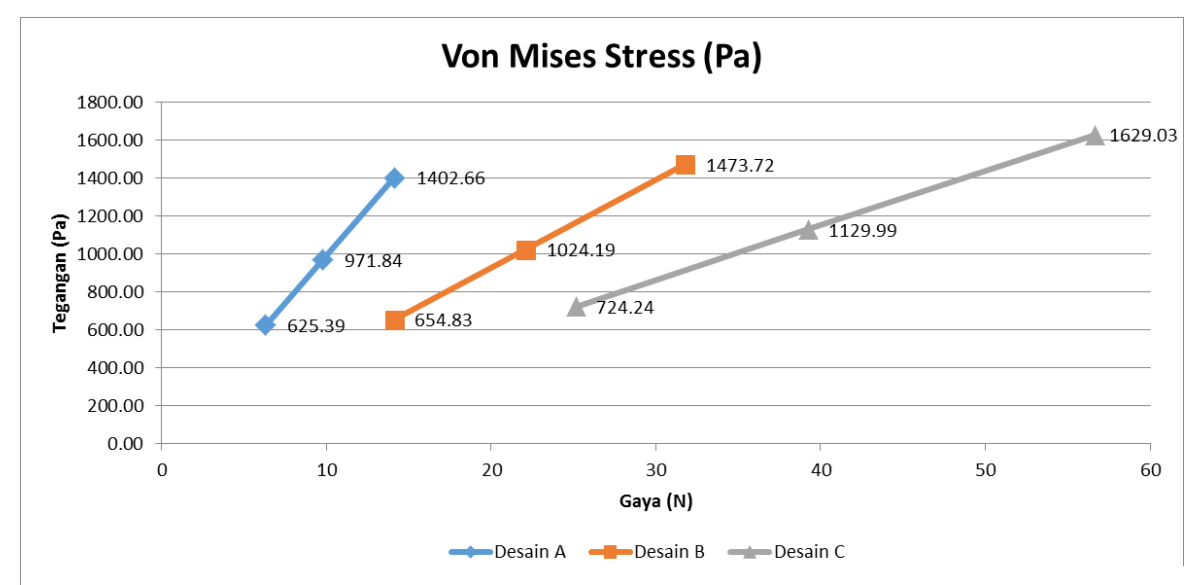

Gambar 11. Grafik besar gaya terhadap maksimum von mises stress

Dalam grafik diatas ditunjukan perbandingan nilai maksimum von mises stress dari sudu turbin desain A, desain B, dan desain $\mathrm{C}$ yang telah disimulasikan dengan beban angin 20, 25, $30 \mathrm{~m} / \mathrm{s}$. Maka dari hasil tersebut dapat diketahui seiring beban yang diberikan dan dimensi desain sudu turbin bertambah maka hasil nilai von mises stress akan naik. Von mises stress tertinggi pada desain C sebesar $1629 \mathrm{~Pa}$ dengan input gaya $56.67 \mathrm{~N}$.

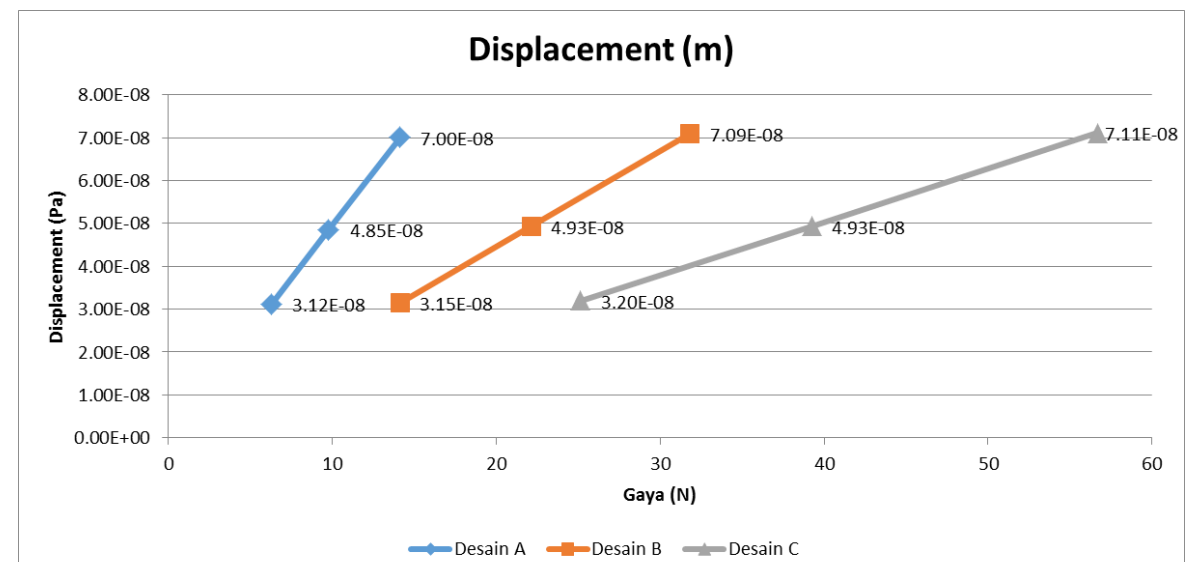

Gambar 14. Grafik besar gaya terhadap maksimum Displacement 
Dalam grafik diatas ditunjukan perbandingan nilai maksimum displacement dari sudu turbin desain A, desain $B$, dan desain $C$ yang telah disimulasikan dengan beban angin 20, 25, $30 \mathrm{~m} / \mathrm{s}$. Maka dari hasil tersebut dapat diketahui seiring beban yang diberikan dan dimensi desain sudu turbin bertambah maka hasil nilai displacement akan naik. Displacement tertinggi pada desain C sebesar 7.1096e-8 m dengan input gaya 56.67 N.

\section{KESIMPULAN}

Desain sudu dengan variasi desain dan kecepatan angin memiliki pengaruh terhadap distribusi stress dan displacement, dengan ukuran desain sudu yang lebih luas serta kecepatan angin yang semakin tinggi maka nilai daya dan gaya yang dihasilkan semakin besar, nilai gaya ini yang akan berpengaruh pada hasil simulasi. Nilai stress dan displacement akan bertambah jika nilai gaya yang bekerja naik. Letak distribusi stress maksimal terjadi pada sambungan antara sudu dengan pegangan yang merupakan tumpuan beban dari berat keseluruhan sudu. Sedangkan letak displacement maskimal terjadi pada bagian depan sudu yang memiliki ketebalan yang lebih tipis. Dari hasil simulasi didapatkan bahwa material yang digunakan yaitu baja AISI 1020 masih aman jika nilai stress dan displacement maksimal sudu turbin dibandingkan dengan batas aman pada mechanical properties baja AISI 1020.

\section{UCAPAN TERIMA KASIH}

Penulis mengucapkan terima kasih kepada Program Studi Teknik Mesin-Universitas Pamulang dan Pusat Penelitian Fisika-Lembaga Ilmu Pengetahuan Indonesia atas dukungan dalam penelitian ini.

\section{DAFTAR PUSTAKA}

[1] A. Murtadho, "Perancangan Turbin Angin Skala Rumah Tinggal", Malang, Universitas Muhammadiyah Malang, 2018.

[2] A. Hemami, "Wind turbine technology", Cengage Learning, 2012.

[3] A. A. Sahadewa, "Redesain Overhead Crane dengan Analisa Kegagalan di PLTU Paiton Berbasis Metode Elemen Hingga", Surabaya, Institut Teknologi Sepuluh Nopember, 2017.

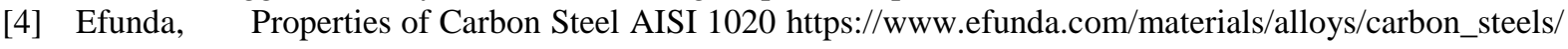
show_carbon.cfm?ID=AISI_1020\&show_prop=all\&Page_Title=AISI\%201020, 2020.

[5] G. Y. Huang, Y. C. Shiah, C. J. Bai, and W. T. Chong, "Experimental study of the protuberance effect on the blade performance of a small horizontal axis wind turbine," J. Wind Eng. Ind. Aerodyn., vol. 147, pp. 202-211, 2015.

[6] P. Gipe, "Wind power renewable energy for home farm and business", Chelsia Green Publication Company, White River Junction, VT, Page no. 61, 2004. 